\title{
Trends in the utilization of radiotherapy for spinal meningiomas: insights from the 2004-2015 National Cancer Database
}

\author{
*Yagiz Ugur Yolcu, MD, Anshit Goyal, MBBS, Mohammed Ali Alvi, MBBS, \\ FM Moinuddin, MBBS, PhD, and Mohamad Bydon, MD \\ Mayo Clinic Neuro-Informatics Laboratory, and Department of Neurologic Surgery, Mayo Clinic, Rochester, Minnesota
}

OBJECTIVE Recent studies have reported on the utility of radiosurgery for local control and symptom relief in spinal meningioma. The authors sought to evaluate national utilization trends in radiotherapy (including radiosurgery), investigate possible factors associated with its use in patients with spinal meningioma, and its impact on survival for atypical tumors.

METHODS Using the ICD-0-3 topographical codes C70.1, C72.0, and C72.1 and histological codes 9530-9535 and 9537-9539, the authors queried the National Cancer Database for patients in whom spinal meningioma had been diagnosed between 2004 and 2015. Patients who had undergone radiation in addition to surgery and those who had received radiation as the only treatment were analyzed for factors associated with each treatment.

RESULTS From among 10,458 patients with spinal meningioma in the database, the authors found a total of 268 patients who had received any type of radiation. The patients were divided into two main groups for the analysis of radiation alone (137 [51.1\%]) and radiation plus surgery (131 [48.9\%]). An age > 69 years $(p<0.001)$, male sex $(p=0.03)$, and tumor size 5 to $<6 \mathrm{~cm}(p<0.001)$ were found to be associated with significantly higher odds of receiving radiation alone, whereas a Charlson-Deyo Comorbidity Index $\geq 2(p=0.01)$ was associated with significantly lower odds of receiving radiation alone. Moreover, a larger tumor size $(2$ to $<3 \mathrm{~cm}, p=0.01 ; 3$ to $<4 \mathrm{~cm}, p<0.001 ; 4$ to $<5 \mathrm{~cm}, p<0.001 ; 5$ to $<6 \mathrm{~cm}, p<0.001$; and $\geq 6 \mathrm{~cm}, p<0.001$; reference $=1$ to $<2 \mathrm{~cm})$, as well as borderline $(p<0.001)$ and malignant $(p<$ 0.001 ) tumors were found to be associated with increased odds of undergoing radiation in addition to surgery. Receiving adjuvant radiation conferred a significant reduction in overall mortality among patients with borderline or malignant spinal meningiomas (HR 2.12, 95\% Cl 1.02-4.1, $p=0.02$ ).

CONCLUSIONS The current analysis of cases from a national cancer database revealed a small increase in the use of radiation for the management of spinal meningioma without a significant increase in overall survival. Larger tumor size and borderline or malignant behavior were found to be associated with increased radiation use. Data in the present analysis failed to show an overall survival benefit in utilizing adjuvant radiation for atypical tumors.

https://thejns.org/doi/abs/10.3171/2019.3.FOCUS1969

KEYWORDS meningioma; radiotherapy; radiosurgery; national cancer database; trends; survival; spine tumor; spine neoplasms; Gamma Knife; adjuvant radiation

$\mathrm{M}$ ENINGIOMAS are one of the most frequently encountered tumor types in the spinal cord, accounting for $20 \%-25 \%$ of all spine tumors. ${ }^{2}$ Approximately 5\%-14\% of spinal meningiomas are extradural, while the rest are mostly intradural extramedullary tumors. ${ }^{11}$ The majority of these tumors are benign, but a small percentage can present as borderline or malignant lesions, defined as grade II or III according to the World Health Organization (WHO) classification. ${ }^{22}$

Spinal meningiomas can be asymptomatic and diagnosed incidentally; however, they can also present with symptoms of spinal cord compression including pain and impairment in motor or sensory function. ${ }^{12}$ Treatment strategies include observation (active surveillance),

ABBREVIATIONS EBRT = external beam radiotherapy; NCDB = National Cancer Database SRS $=$ stereotactic radiosurgery .

SUBMITTED February 1, 2019. ACCEPTED March 21, 2019.

INCLUDE WHEN CITING DOI: 10.3171/2019.3.FOCUS1969.

* Y.U.Y. and A.G. contributed equally to this paper. 


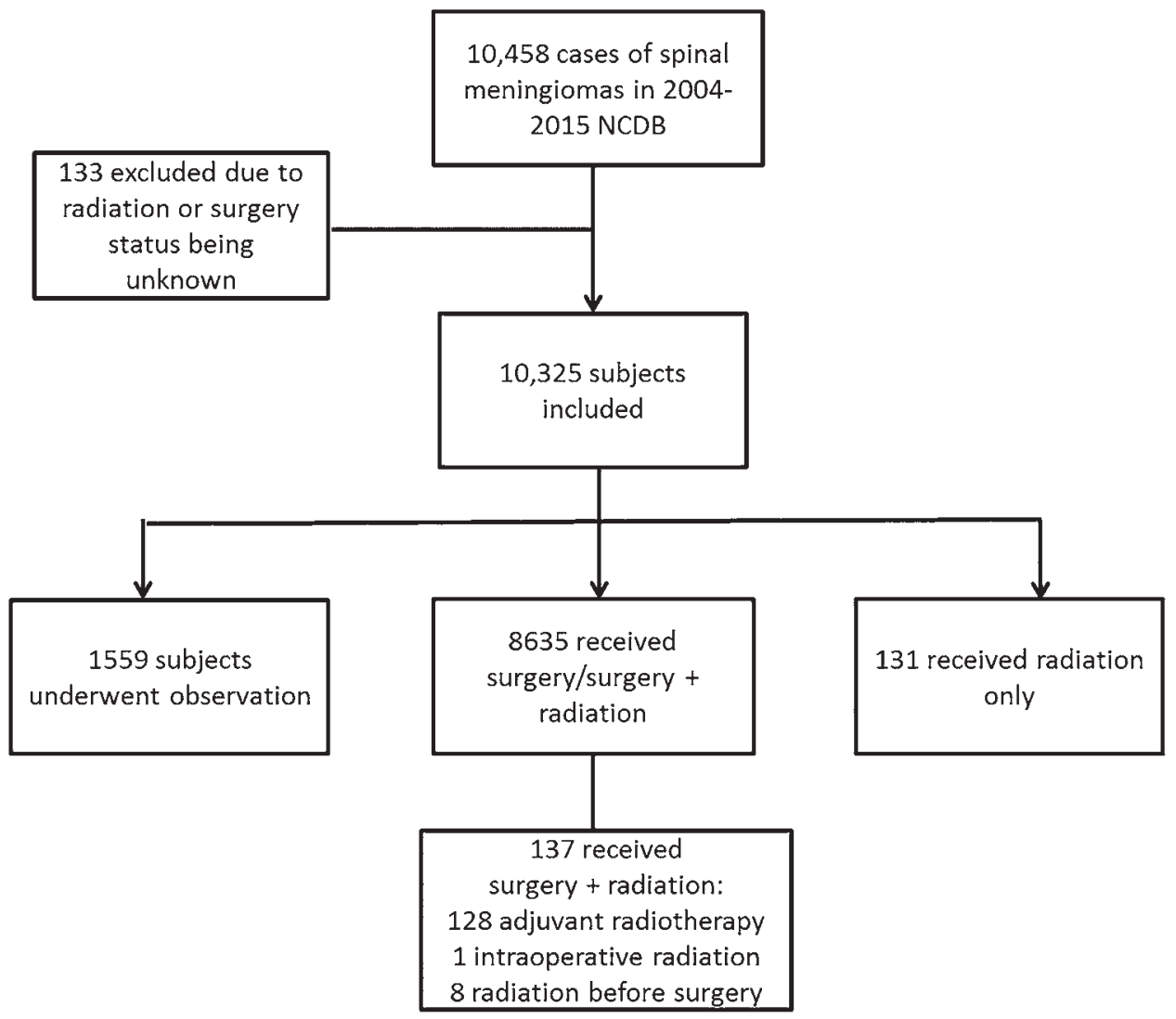

FIG. 1. Flowchart of patient selection and treatment stratification.

excision, radiotherapy, radiosurgery, or a combination of modalities..$^{18}$ Surgery continues to be the most frequently utilized treatment modality, but radiotherapy is also an option most commonly reserved for high-grade or recurrent lesions ${ }^{17}$ Existing literature on the role of radiotherapy and radiosurgery for spinal meningioma is limited to singleinstitution studies, which have purported a beneficial role of radiosurgery in terms of both local control and symptom relief..$^{24}$ However, there remains a paucity of literature on the true rate of the use of radiotherapy for spinal meningioma and its impact on overall survival.

In light of this knowledge gap, we performed an analysis based on a national database including patients diagnosed with spinal meningioma to evaluate national utilization trends for radiotherapy and radiosurgery and investigate possible factors associated with their use. We also aimed to determine if radiotherapy alone or combined with surgery confers an overall survival benefit as compared to that obtained with surgery alone.

\section{Methods}

\section{Data Source and Patient Cohort}

The National Cancer Database (NCDB) was queried for patients in whom spinal meningioma had been diagnosed between 2004 and 2015 and who had received any type of radiation treatment. The NCDB, one of the largest cancer registries in the United States, contains almost 34 million cases from over 1500 hospitals. Data are collected from selected health registries accredited by the American College of Surgeons' Commission on Cancer (https:// www.facs.org/quality\%20 programs/cancer/coc).

We used the ICD-O-3 histological codes designating meningioma (9530-9535 and 9537-9539) and ICD-O-3 topographical codes for spinal meninges (C70.1), spinal cord (C72.0), and cauda equina (C72.1) to identify pertinent cases. The NCDB Participant User Data File consists of de-identified cases and is therefore exempt from institutional review board approval.

\section{Outcomes of Interest}

Type of treatment constituted the primary outcome of interest. Patients were classified as 1) undergoing observation only (no surgery or radiation received), 2) undergoing surgery, or 3) receiving radiation alone as the primary treatment (with no surgery at the primary site). In a separate analysis, we further stratified patients in the second category (surgery) as those who underwent surgery alone and those who received radiation in addition to surgery. Furthermore, we took into account the sequence of radiotherapy administration and performed a stratified analysis for the adjuvant mode of radiotherapy. Baseline patient characteristics, hospital characteristics, and tumor characteristics were analyzed for each group.

\section{Covariates}

The following variables were recorded: 1) patient 
TABLE 1. Baseline characteristics of patients undergoing radiation treatment

\begin{tabular}{|c|c|c|c|}
\hline Variable & Adjuvant Radiation & Radiation Only & Radiation + Surgery \\
\hline No. of patients & 128 & 131 & 137 \\
\hline Median age in yrs (range) & $56(9-86)$ & $71(14-90)$ & $56(9-88)$ \\
\hline Female sex, no. (\%) & $87(68.0)$ & $94(71.8)$ & $93(67.9)$ \\
\hline Median FU time in mos (range) & $50.5(3.6-151.0)$ & $48.3(0.39-124)$ & $52.0(3.6-151)$ \\
\hline \multicolumn{4}{|l|}{ Race, no. (\%) } \\
\hline White & $103(80.5)$ & $112(85.5)$ & $109(79.6)$ \\
\hline African American & $22(17.2)$ & $14(10.6)$ & $23(16.8)$ \\
\hline Other & $2(1.6)$ & $4(3.1)$ & $3(2.2)$ \\
\hline Unknown & $1(0.8)$ & $1(0.8)$ & $2(1.5)$ \\
\hline \multicolumn{4}{|l|}{ Charlson-Deyo Comorbidity Index, no. (\%) } \\
\hline 0 & $102(79.7)$ & $105(80.2)$ & $111(81.0)$ \\
\hline 1 & $14(10.9)$ & $21(16.0)$ & $14(10.2)$ \\
\hline 2 & $12(9.4)$ & $5(3.8)$ & $12(8.8)$ \\
\hline \multicolumn{4}{|l|}{ Insurance status, no. (\%) } \\
\hline Not insured & $2(1.6)$ & $3(2.3)$ & $2(1.5)$ \\
\hline Private insurance & $78(60.9)$ & $43(32.8)$ & $83(60.6)$ \\
\hline Medicaid & $13(10.2)$ & $4(3.1)$ & $13(9.5)$ \\
\hline Medicare & $33(25.8)$ & $74(56.5)$ & $37(27.0)$ \\
\hline Other government & $0(0)$ & $4(3.1)$ & $0(0)$ \\
\hline Unknown & $2(1.6)$ & $3(2.3)$ & $2(1.5)$ \\
\hline \multicolumn{4}{|l|}{ Facility type, no. (\%) } \\
\hline Community Cancer Program & $3(2.3)$ & $6(4.6)$ & $4(2.9)$ \\
\hline Comprehensive Community Cancer Program & $26(20.3)$ & $53(40.5)$ & $27(19.7)$ \\
\hline Academic/research program & $56(43.8)$ & $49(37.4)$ & $60(43.8)$ \\
\hline Integrated Network Cancer Program & $16(12.5)$ & $20(15.3)$ & $17(12.4)$ \\
\hline Unknown & $27(21.1)$ & $3(2.3)$ & $29(21.2)$ \\
\hline \multicolumn{4}{|l|}{ Tumor size in largest dimension in cm, no. (\%) } \\
\hline$<1$ & $3(2.3)$ & $12(9.2)$ & $3(2.2)$ \\
\hline 1 to $<2$ & $11(8.6)$ & $43(32.8)$ & $12(8.8)$ \\
\hline 2 to $<3$ & $21(16.4)$ & $25(19.1)$ & $23(16.8)$ \\
\hline 3 to $<4$ & $10(7.8)$ & $10(7.6)$ & $10(7.3)$ \\
\hline 4 to $<5$ & $11(8.6)$ & $3(2.3)$ & $11(8.0)$ \\
\hline 5 to $<6$ & $8(6.3)$ & $4(3.1)$ & $8(5.8)$ \\
\hline$\geq 6$ & $8(6.3)$ & $9(6.9)$ & $9(6.6)$ \\
\hline Data missing & $56(43.8)$ & $25(19.1)$ & $61(44.5)$ \\
\hline \multicolumn{4}{|l|}{ Tumor behavior, no. (\%) } \\
\hline Benign & $75(58.6)$ & $129(98.5)$ & $81(59.1)$ \\
\hline Borderline & $35(27.3)$ & $1(0.8)$ & $37(27.0)$ \\
\hline Malignant & $18(14.1)$ & $1(0.8)$ & $19(13.9)$ \\
\hline \multicolumn{4}{|l|}{ Type of radiotherapy, no. (\%) } \\
\hline EBRT & $99(77.3)$ & $51(38.9)$ & $105(76.6)$ \\
\hline Radiosurgery & $29(22.7)$ & $80(61.1)$ & $31(22.6)$ \\
\hline Brachytherapy & $0(0)$ & $0(0)$ & $1(0.7)$ \\
\hline \multicolumn{4}{|l|}{ Mean radiation dose in Gy (SD) } \\
\hline EBRT & $50.4(5-540)$ & $30(6-100)$ & $50.4(2.5-540)$ \\
\hline Radiosurgery & $24(2.1-200)$ & $24(8-100)$ & $24(10-200)$ \\
\hline
\end{tabular}

$\mathrm{FU}=$ follow-up. 


\section{Utilization Rate of Radiation Alone For Spinal Meningioma 2004-2015}

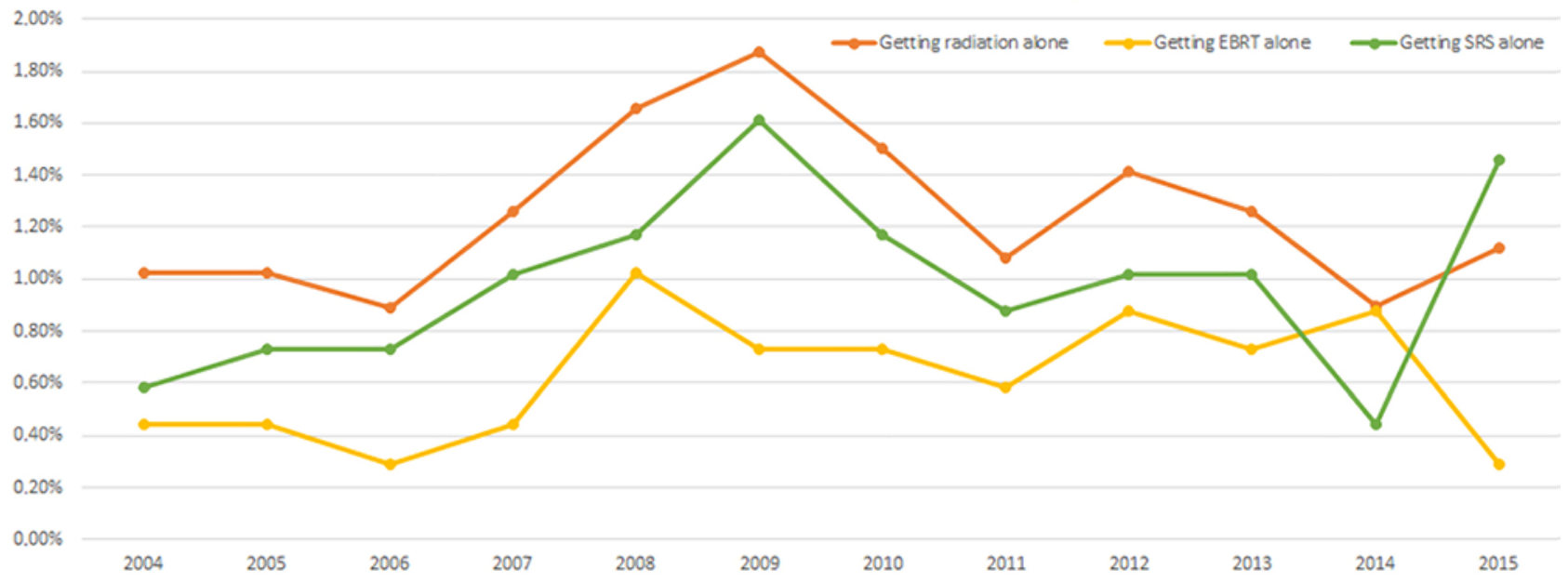

Utilization Rate of Adjuvant Radiation For Spinal Meningioma 2004-2015

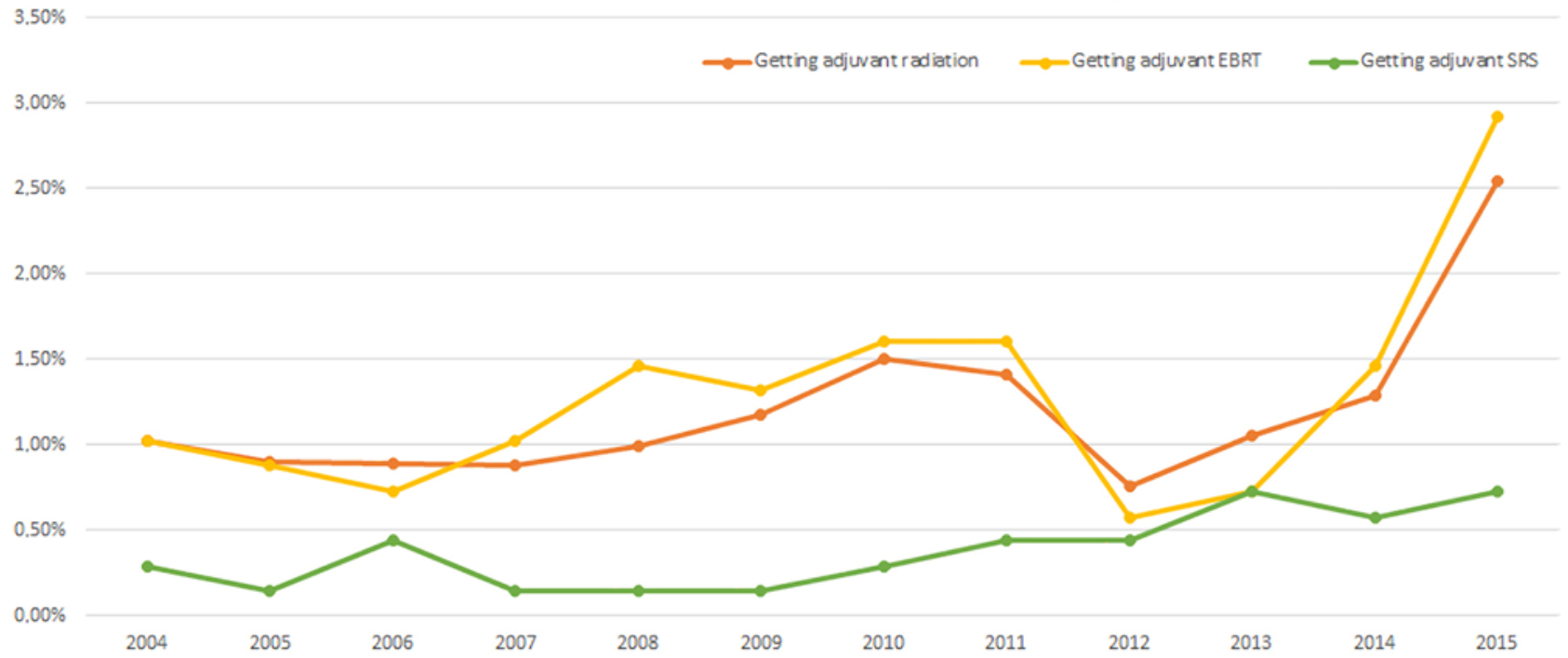

FIG. 2. Utilization rate of radiation alone (upper) and adjuvant radiation (lower) for spinal meningioma in 2004-2015.

demographics: age $(<50,50-69,>69$ years), sex, race, Charlson-Deyo Comorbidity Index, ${ }^{6}$ insurance status, and year of diagnosis; 2) type of reporting facility; 3) tumor size, grade, and behavior; and 4) treatment parameters: surgical treatment, additional radiotherapy, and type and timing of radiotherapy.

\section{Statistical Analysis}

Descriptive statistics are presented as the mean and standard deviation or the median and range for continuous variables and frequency and percentages for categorical variables.

Multivariable logistic regression analysis was performed to determine the factors associated with different treatment modalities while adjusting for age, sex, race, tumor size, and tumor behavior. We divided our analyses into three different models: model 1, fitted to predict the primary treatment modality "radiation only" versus sur- gery or observation (dichotomous); model 2, fitted to predict the use of radiation in addition to surgery regardless of the sequence of administration (subsetting of the data set for those who underwent surgery); model 3, fitted to predict utilization of "adjuvant radiation" following surgery (subsetting of the data set for those who underwent primary surgery with no prior treatment). While performing an analysis with adjuvant radiation as the primary outcome, the extent of resection was also included as a covariate. Patients whose surgery or radiation status was classified as unknown were excluded from the analysis.

In addition, Kaplan-Meier analysis was performed to assess the impact of adjuvant radiation on survival following surgery for atypical/malignant spinal meningiomas. We also performed multivariate Cox regression to adjust for age, sex, Charlson-Deyo Comorbidity Index, tumor size, tumor behavior, and extent of resection. To avoid overfitting, we did not add more than one predictor for every 10 outcome events (deaths) in the Cox regres- 
TABLE 2. Characteristics of patients receiving radiation alone

\begin{tabular}{|c|c|c|c|c|}
\hline Variable & EBRT & SRS & Total & $\begin{array}{c}p \\
\text { Value }\end{array}$ \\
\hline No. of patients & 51 & 80 & 131 & \\
\hline Age in yrs & & & & 0.003 \\
\hline$<50$ & $3(5.9 \%)$ & $8(10.0 \%)$ & $11(8.4 \%)$ & \\
\hline$>69$ & $36(70.6 \%)$ & $32(40.0 \%)$ & $68(51.9 \%)$ & \\
\hline $50-69$ & $12(23.5 \%)$ & $40(50.0 \%)$ & $52(39.7 \%)$ & \\
\hline Sex & & & & 0.576 \\
\hline Male & $13(25.5 \%)$ & $24(30.0 \%)$ & $37(28.2 \%)$ & \\
\hline Female & $38(74.5 \%)$ & $56(70.0 \%)$ & $94(71.8 \%)$ & \\
\hline Race & & & & $0.342^{*}$ \\
\hline Non-Hispanic white & $37(72.5 \%)$ & $67(83.8 \%)$ & $104(79.4 \%)$ & \\
\hline Hispanic & $5(9.8 \%)$ & $2(2.5 \%)$ & $7(5.3 \%)$ & \\
\hline $\begin{array}{l}\text { Non-Hispanic } \\
\text { Asian/Pacific } \\
\text { Islander }\end{array}$ & $2(3.9 \%)$ & $2(2.5 \%)$ & $4(3.1 \%)$ & \\
\hline Non-Hispanic black & $6(11.8 \%)$ & $8(10.0 \%)$ & $14(10.7 \%)$ & \\
\hline $\begin{array}{l}\text { Other/unknown, } \\
\text { non-Hispanic }\end{array}$ & $1(2.0 \%)$ & $1(1.2 \%)$ & $2(1.5 \%)$ & \\
\hline Yr of diagnosis & & & & $0.839^{*}$ \\
\hline 2004 & $3(5.9 \%)$ & $4(5.0 \%)$ & $7(5.3 \%)$ & \\
\hline 2005 & $3(5.9 \%)$ & $5(6.3 \%)$ & $8(6.1 \%)$ & \\
\hline 2006 & $2(3.9 \%)$ & $5(6.3 \%)$ & $7(5.3 \%)$ & \\
\hline 2007 & $3(5.9 \%)$ & $7(8.8 \%)$ & $10(7.6 \%)$ & \\
\hline 2008 & $7(13.7 \%)$ & $8(10.0 \%)$ & $15(11.5 \%)$ & \\
\hline 2009 & $5(9.8 \%)$ & $11(13.8 \%)$ & $16(12.2 \%)$ & \\
\hline 2010 & $5(9.8 \%)$ & $8(10.0 \%)$ & $13(9.9 \%)$ & \\
\hline 2011 & $4(7.8 \%)$ & $6(7.5 \%)$ & $10(7.6 \%)$ & \\
\hline 2012 & $6(11.8 \%)$ & $7(8.8 \%)$ & $13(9.9 \%)$ & \\
\hline 2013 & $5(9.8 \%)$ & $7(8.8 \%)$ & $12(9.2 \%)$ & \\
\hline 2014 & $6(11.8 \%)$ & $3(3.8 \%)$ & $9(6.9 \%)$ & \\
\hline 2015 & $2(3.9 \%)$ & $9(11.3 \%)$ & $11(8.4 \%)$ & \\
\hline Insurance status & & & & $0.034^{*}$ \\
\hline Medicare & $30(58.8 \%)$ & $44(55.0 \%)$ & $74(56.5 \%)$ & \\
\hline Uninsured & $2(3.9 \%)$ & $1(1.3 \%)$ & $3(2.3 \%)$ & \\
\hline Private & $12(23.5 \%)$ & $31(38.8 \%)$ & $43(32.8 \%)$ & \\
\hline Medicaid & $4(7.8 \%)$ & $0(0.0 \%)$ & $4(3.1 \%)$ & \\
\hline Other/unknown & $3(5.9 \%)$ & $4(5.0 \%)$ & $7(5.3 \%)$ & \\
\hline Tumor size† & & & & 0.976 \\
\hline$<3 \mathrm{~cm}$ & $29(78.4 \%)$ & $50(62.5 \%)$ & $79(78.2 \%)$ & \\
\hline$>3 \mathrm{~cm}$ & $8(21.6 \%)$ & $14(17.5 \%)$ & $22(21.8 \%)$ & \\
\hline
\end{tabular}

Boldface type indicates statistical significance.

* Fisher's exact test was utilized.

† Data missing for 14 EBRT cases and 16 SRS cases.

sion model. Patients diagnosed in the year 2015 were excluded from survival analysis given the lack of follow-up regarding vital status. For all analyses, the level of statistical significance was established at $\mathrm{p}<0.05$. All statistical analyses were performed using R statistical software version 3.4.1 (R Foundation for Statistical Computing; https:// www.R-project.org/).
TABLE 3. Characteristics of patients undergoing adjuvant radiotherapy

\begin{tabular}{|c|c|c|c|c|}
\hline Variable & EBRT & SRS & Total & $p$ Value \\
\hline No. of patients & 93 & 33 & 126 & \\
\hline Age in yrs & & & & 0.838 \\
\hline$<50$ & $36(38.7 \%)$ & $11(33.3 \%)$ & $47(37.3 \%)$ & \\
\hline$>69$ & $17(18.3 \%)$ & $6(18.2 \%)$ & $23(18.3 \%)$ & \\
\hline $50-69$ & $40(43.0 \%)$ & $16(48.5 \%)$ & $56(44.4 \%)$ & \\
\hline Sex & & & & 0.84 \\
\hline Male & $30(32.3 \%)$ & $10(30.3 \%)$ & $40(31.7 \%)$ & \\
\hline Female & $63(67.7 \%)$ & $23(69.7 \%)$ & $86(68.3 \%)$ & \\
\hline Race & & & & $0.26^{*}$ \\
\hline Non-Hispanic white & $68(73.1 \%)$ & $19(57.6 \%)$ & $87(69.0 \%)$ & \\
\hline Hispanic & $3(3.2 \%)$ & $2(6.1 \%)$ & $5(4.0 \%)$ & \\
\hline $\begin{array}{l}\text { Non-Hispanic } \\
\text { Asian/Pacific } \\
\text { Islander }\end{array}$ & $1(1.1 \%)$ & $1(3.0 \%)$ & $2(1.6 \%)$ & \\
\hline Non-Hispanic black & $15(16.1 \%)$ & $6(18.2 \%)$ & $21(16.7 \%)$ & \\
\hline $\begin{array}{l}\text { Other/unknown, } \\
\text { non-Hispanic }\end{array}$ & $6(6.5 \%)$ & $5(15.2 \%)$ & $11(8.7 \%)$ & \\
\hline Yr of diagnosis & & & & $0.66^{*}$ \\
\hline 2004 & $4(4.3 \%)$ & $3(9.1 \%)$ & $7(5.6 \%)$ & \\
\hline 2005 & $5(5.4 \%)$ & $1(3.0 \%)$ & $6(4.8 \%)$ & \\
\hline 2006 & $4(4.3 \%)$ & $3(9.1 \%)$ & $7(5.6 \%)$ & \\
\hline 2007 & $6(6.5 \%)$ & $2(6.1 \%)$ & $8(6.3 \%)$ & \\
\hline 2008 & $7(7.5 \%)$ & $2(6.1 \%)$ & $9(7.1 \%)$ & \\
\hline 2009 & $9(9.7 \%)$ & $1(3.0 \%)$ & $10(7.9 \%)$ & \\
\hline 2010 & $11(11.8 \%)$ & $2(6.1 \%)$ & $13(10.3 \%)$ & \\
\hline 2011 & $10(10.8 \%)$ & $3(9.1 \%)$ & $13(10.3 \%)$ & \\
\hline 2012 & $4(4.3 \%)$ & $3(9.1 \%)$ & $7(5.6 \%)$ & \\
\hline 2013 & $5(5.4 \%)$ & $5(15.2 \%)$ & $10(7.9 \%)$ & \\
\hline 2014 & $10(10.8 \%)$ & $3(9.1 \%)$ & $13(10.3 \%)$ & \\
\hline 2015 & $18(19.4 \%)$ & $5(15.2 \%)$ & $23(18.3 \%)$ & \\
\hline Insurance status & & & & $0.93^{*}$ \\
\hline Medicare & $25(26.9 \%)$ & $9(27.3 \%)$ & $34(27.0 \%)$ & \\
\hline Uninsured & $2(2.2 \%)$ & $0(0.0 \%)$ & $2(1.6 \%)$ & \\
\hline Private & $55(59.1 \%)$ & $20(60.6 \%)$ & $75(59.5 \%)$ & \\
\hline Medicaid & $10(10.8 \%)$ & $3(9.1 \%)$ & $13(10.3 \%)$ & \\
\hline Other/unknown & $1(1.1 \%)$ & $1(3.0 \%)$ & $2(1.6 \%)$ & \\
\hline Tumor size† & & & & 0.12 \\
\hline$<3 \mathrm{~cm}$ & $29(54.7 \%)$ & $6(33.3 \%)$ & $35(49.3 \%)$ & \\
\hline$>3 \mathrm{~cm}$ & $24(45.3 \%)$ & $12(66.7 \%)$ & $36(50.7 \%)$ & \\
\hline Extent of resection $\ddagger$ & & & & 0.36 \\
\hline GTR & $37(63.8 \%)$ & $11(52.4 \%)$ & $48(60.8 \%)$ & \\
\hline Biopsy/STR & $21(36.2 \%)$ & $10(47.6 \%)$ & $31(39.2 \%)$ & \\
\hline \multicolumn{5}{|c|}{$\begin{array}{l}\text { GTR = gross-total resection; STR = subtotal resection. } \\
\text { Two cases that received proton beam radiotherapy are not included. } \\
\text { *Fisher's exact test for count data. } \\
\text { † Tumor size was missing in } 40 \text { EBRT cases and } 15 \text { SRS cases. } \\
\text { † Extent of resection was missing in } 35 \text { EBRT cases and } 12 \text { SRS case }\end{array}$} \\
\hline
\end{tabular}


TABLE 4. Multivariable analysis for factors associated with increased utilization of each treatment modality

\begin{tabular}{|c|c|c|c|c|c|c|}
\hline \multirow[b]{2}{*}{ Variable } & \multicolumn{2}{|c|}{ Radiation Only ( $\mathrm{n}=131)$} & \multicolumn{2}{|c|}{ Any Radiation + Surgery $(n=137)$} & \multicolumn{2}{|c|}{ Adjuvant Radiation $(n=128)$} \\
\hline & OR $(95 \% \mathrm{Cl})$ & p Value & OR $(95 \% \mathrm{Cl})$ & $p$ Value & OR $(95 \% \mathrm{Cl})$ & $\mathrm{p}$ Value \\
\hline \multicolumn{7}{|l|}{ Tumor size in $\mathrm{cm}$} \\
\hline 1 to $<2$ & Reference & & Reference & & Reference & \\
\hline$<1$ & $1.29(0.66-2.53)$ & 0.46 & $2.44(0.66-8.98)$ & 0.18 & $2.67(0.72-9.85)$ & 0.14 \\
\hline 2 to $<3$ & $0.93(0.56-1.53)$ & 0.77 & $2.51(1.23-5.15)$ & 0.01 & $2.28(1.10-4.74)$ & 0.03 \\
\hline 3 to $<4$ & $1.83(0.91-3.70)$ & 0.09 & $4.32(1.78-10.5)$ & 0.00 & $4.40(1.81-10.7)$ & 0.001 \\
\hline 4 to $<5$ & $1.76(0.53-5.83)$ & 0.35 & $19.2(7.65-48.4)$ & $<0.001$ & $17.4(6.73-44.7)$ & $<0.001$ \\
\hline 5 to $<6$ & $4.87(1.63-14.5)$ & $<0.001$ & $23.0(7.66-69.2)$ & $<0.001$ & $23.5(7.76-71.1)$ & $<0.001$ \\
\hline$\geq 6$ & $2.33(0.9-6.1)$ & 0.08 & $8.17(2.95-22.63)$ & $<0.001$ & $7.36(2.51-21.5)$ & $<0.001$ \\
\hline Missing data & $0.52(0.32-0.83)$ & 0.01 & $3.45(1.82-6.55)$ & $<0.001$ & $3.24(1.70-6.18)$ & $<0.001$ \\
\hline \multicolumn{7}{|l|}{ Age } \\
\hline$<50$ & Reference & & Reference & & Reference & \\
\hline $50-69$ & $2.36(1.21-4.61)$ & 0.01 & $0.89(0.58-1.37)$ & 0.61 & $0.96(0.62-1.50)$ & 0.87 \\
\hline$>69$ & $3.51(1.67-7.39)$ & $<0.001$ & $0.70(0.36-1.37)$ & 0.30 & $0.74(0.37-1.48)$ & 0.39 \\
\hline \multicolumn{7}{|l|}{ Sex } \\
\hline Male & Reference & & Reference & & Reference & \\
\hline Female & $0.64(0.43-0.95)$ & 0.03 & $0.76(0.51-1.14)$ & 0.18 & $0.80(0.52-1.21)$ & 0.29 \\
\hline \multicolumn{7}{|l|}{ Race } \\
\hline White & Reference & & Reference & & Reference & \\
\hline Hispanic & $1.26(0.57-2.76)$ & 0.57 & $0.85(0.35-2.06)$ & 0.71 & $0.74(0.28-1.95)$ & 0.55 \\
\hline African American & $1.57(0.88-2.80)$ & 0.12 & $2.19(1.29-3.73)$ & 0.004 & $2.05(1.18-3.54)$ & 0.01 \\
\hline Asian/Pacific Islander & $0.95(0.35-2.62)$ & 0.93 & $0.64(0.19-2.13)$ & 0.47 & $0.45(0.10-1.90)$ & 0.27 \\
\hline Other/unknown & $0.22(0.05-0.89)$ & 0.03 & $1.41(0.75-2.66)$ & 0.29 & $1.24(0.63-2.45)$ & 0.53 \\
\hline \multicolumn{7}{|c|}{ Charlson-Deyo Comorbidity Index } \\
\hline 0 & Reference & & Reference & & Reference & \\
\hline 1 & $0.71(0.44-1.14)$ & 0.16 & $0.53(0.29-0.97)$ & 0.04 & $0.57(0.31-1.03)$ & 0.06 \\
\hline$\geq 2$ & $0.30(0.12-0.75)$ & 0.01 & $0.80(0.42-1.52)$ & 0.49 & $0.84(0.44-1.63)$ & 0.62 \\
\hline \multicolumn{7}{|l|}{ Insurance status } \\
\hline Medicare & Reference & & Reference & & Reference & \\
\hline Uninsured & $0.95(0.35-2.62)$ & 0.93 & $0.43(0.09-2.01)$ & 0.28 & $0.49(0.10-2.32)$ & 0.37 \\
\hline Private & $0.98(0.61-1.58)$ & 0.94 & $1.60(0.95-2.71)$ & 0.08 & $1.69(0.97-2.92)$ & 0.06 \\
\hline Medicaid & $0.77(0.26-2.22)$ & 0.63 & $2.00(0.92-4.37)$ & 0.08 & $2.35(1.06-5.19)$ & 0.03 \\
\hline Other/unknown & $2.44(1.08-5.54)$ & 0.03 & $0.80(0.18-3.50)$ & 0.77 & $0.89(0.20-3.94)$ & 0.88 \\
\hline \multicolumn{7}{|l|}{ Yr of diagnosis } \\
\hline 2004 & Reference & & Reference & & Reference & \\
\hline 2005 & $0.99(0.36-2.77)$ & 0.99 & $0.99(0.35-2.84)$ & 0.99 & $1.36(0.45-4.16)$ & 0.59 \\
\hline 2006 & $0.90(0.31-2.60)$ & 0.85 & $0.98(0.36-2.68)$ & 0.97 & $1.02(0.33-3.17)$ & 0.97 \\
\hline 2007 & $1.27(0.48-3.37)$ & 0.63 & $1.16(0.42-3.21)$ & 0.78 & $1.57(0.53-4.68)$ & 0.42 \\
\hline 2008 & $1.59(0.64-3.96)$ & 0.32 & $1.25(0.48-3.27)$ & 0.64 & $1.37(0.47-4.00)$ & 0.56 \\
\hline 2009 & $1.72(0.70-4.25)$ & 0.24 & $1.43(0.54-3.78)$ & 0.47 & $1.96(0.69-5.57)$ & 0.20 \\
\hline 2010 & $1.35(0.53-3.44)$ & 0.53 & $1.96(0.78-4.93)$ & 0.15 & $1.58(0.13-19.9)$ & 0.72 \\
\hline 2011 & $0.99(0.37-2.62)$ & 0.98 & $1.50(0.59-3.79)$ & 0.39 & $1.35(0.11-17.3)$ & 0.82 \\
\hline 2012 & $1.17(0.46-2.97)$ & 0.74 & $1.00(0.34-2.94)$ & 0.99 & $0.9(0.07-12.0)$ & 0.94 \\
\hline 2013 & $1.09(0.42-2.81)$ & 0.86 & $1.36(0.52-3.57)$ & 0.54 & $1.33(0.10-17.2)$ & 0.83 \\
\hline 2014 & $0.72(0.26-1.95)$ & 0.52 & $1.76(0.71-4.37)$ & 0.22 & $1.63(0.13-20.4)$ & 0.71 \\
\hline 2015 & $0.92(0.35-2.42)$ & 0.87 & $3.26(1.14-7.56)$ & 0.01 & $3.26(0.27-39.3)$ & 0.35 \\
\hline \multicolumn{7}{|l|}{ Behavior } \\
\hline Benign & Reference & & Reference & & Reference & \\
\hline Borderline & $0.28(0.04-2.09)$ & 0.22 & $12.4(7.89-19.5)$ & $<0.001$ & $13.4(8.35-21.4)$ & $<0.001$ \\
\hline
\end{tabular}


TABLE 4. Multivariable analysis for factors associated with increased utilization of each treatment modality

\begin{tabular}{|c|c|c|c|c|c|c|}
\hline \multirow[b]{2}{*}{ Variable } & \multicolumn{2}{|c|}{ Radiation Only ( $n=131)$} & \multicolumn{2}{|c|}{ Any Radiation + Surgery $(n=137)$} & \multicolumn{2}{|c|}{ Adjuvant Radiation ( $n=128)$} \\
\hline & OR $(95 \% \mathrm{Cl})$ & p Value & OR $(95 \% \mathrm{Cl})$ & $p$ Value & OR $(95 \% \mathrm{Cl})$ & $\mathrm{p}$ Value \\
\hline \multicolumn{7}{|l|}{ Behavior (continued) } \\
\hline Malignant & $0.77(0.10-5.70)$ & 0.80 & $21.3(11.6-39.2)$ & $<0.001$ & $24.0(12.8-45.1)$ & $<0.001$ \\
\hline \multicolumn{7}{|l|}{ Extent of resection } \\
\hline GTR & Reference & & Reference & & Reference & \\
\hline No GTR & NA & NA & NA & NA & $2.77(1.66-4.62)$ & $<0.001$ \\
\hline Unknown & NA & NA & NA & NA & $0.92(0.09-9.94)$ & 0.94 \\
\hline
\end{tabular}

\section{Results}

\section{Demographic and Treatment Characteristics}

Among all patients who had received radiation, 131 (48.9\%) had radiation alone and $137(51.1 \%)$ had radiation in addition to surgery (Fig. 1). Patients who had radiation alone had a median age of 71 years (range 14-90 years) and those who received radiation in addition to surgery had a median age of 56 years (range 9-88 years). Median follow-up times for radiation alone and surgery plus radiation were 48.3 months (range 0.39-124 months) and 52.0 months (range 3.6-151 months), respectively. Patients who received adjuvant radiation had a median age of 56 years (range 9-86 years) and a median follow-up of 50.5 months (range 3.6-151.0 months). Baseline characteristics of the patients are presented in Table 1.

\section{Tumor and Treatment Characteristics}

For patients who received radiation alone, the majority of tumors (43 [32.8\%]) had diameters from 1 to $<2 \mathrm{~cm}$, followed by tumors with diameters from 2 to $<3 \mathrm{~cm}(25$ [19.1\%]). Among patients who received radiation plus surgery and patients undergoing adjuvant radiation, the majority of tumors had diameters from 2 to $<3 \mathrm{~cm}$ (23 [16.8\%] and 21 [16.4\%], respectively). Radiosurgery was the most common radiation treatment in the patients receiving radiation alone (80 [61.1\%]), whereas external beam radiotherapy (EBRT) was the preferred method for patients undergoing radiation therapy plus surgery (105 [76.6\%]). Tumor and treatment characteristics can be found in more detail in Table 1.

\section{Yearly Utilization of Radiation}

The utilization rates for radiation only and adjuvant radiation were calculated for each year, starting from 2004 until 2015. The rate was calculated as the number of cases receiving adjuvant radiation or radiation alone divided by all cases of spinal meningioma in a given year. The utilization rate for radiation alone was $1.02 \%$ in 2004 and $1.12 \%$ in 2015 with small fluctuations in between. In contrast, adjuvant radiation had a utilization rate of $1.02 \%$ in 2004 and $2.54 \%$ in 2015 , mostly showing a trend toward an increase in utilization. Separate assessment for the utilization of EBRT and stereotactic radiosurgery (SRS) showed an increasing trend for SRS in the patients receiving radia- tion alone, whereas EBRT was the method of choice for patients undergoing adjuvant radiation therapy. A graphic view of utilization rates is presented in Fig. 2.

\section{Multivariable Analysis for Factors Predicting the Use of Radiotherapy}

Tables 2 and 3 summarize the characteristics of patients receiving radiation alone versus adjuvant radiation. On multivariable analysis, we found age $>69$ years $(\mathrm{p}<$ $0.001)$, male sex $(\mathrm{p}=0.03)$, and tumor size from 5 to $<6$ $\mathrm{cm}(\mathrm{p}<0.001)$ to be associated with significantly higher odds of receiving radiation only and a Charlson-Deyo Comorbidity Index $\geq 2(p=0.01)$ to be associated with significantly lower odds of receiving radiation alone. In addition, a larger lesion size ( 2 to $<3 \mathrm{~cm}, \mathrm{p}=0.01 ; 3$ to $<4 \mathrm{~cm}$, $\mathrm{p}<0.001,4$ to $<5 \mathrm{~cm}, \mathrm{p}<0.001,5$ to $<6 \mathrm{~cm}, \mathrm{p}<0.001$ and $\geq 6 \mathrm{~cm}, \mathrm{p}<0.001$; reference $=1$ to $<2 \mathrm{~cm}$ ) and borderline $(\mathrm{p}<0.001)$ and malignant tumors $(\mathrm{p}<0.001)$ were associated with increased odds of receiving radiation in addition to surgery. In a stratified analysis restricted to patients undergoing primary surgery with no prior treatment, larger tumor size and borderline or malignant tumor behavior were associated with increased odds of adjuvant radiation. In addition, patients undergoing subtotal resection were also more likely to receive adjuvant radiation $(\mathrm{p}<0.001)$. In all models, we did not encounter an increase in the use of radiotherapy during successive years (as compared to 2004). Table 4 summarizes the results of all multivariable analyses predicting the use of radiotherapy.

\section{Impact of Adjuvant Radiation on Overall Survival for Atypical Tumors}

Among the patients with borderline or malignant tumors, univariate log-rank statistics demonstrated lower survival in those receiving adjuvant radiotherapy compared to those undergoing surgery alone (5-year survival: $66 \%$ vs $86 \%$, p < 0.001, log-rank; Fig. 3A). These findings were confirmed on a multivariable Cox proportional hazards analysis adjusting for age, sex, tumor size and behavior, and extent of resection, showing a higher risk of mortality with radiation (HR 2.12, 95\% CI 1.02-4.1, p $=0.02$, reference $=$ no radiation). In an analysis further stratifying tumors with malignant behavior only, although a worse 5 -year survival rate was noted with adjuvant radiotherapy 
Yolcu et al.

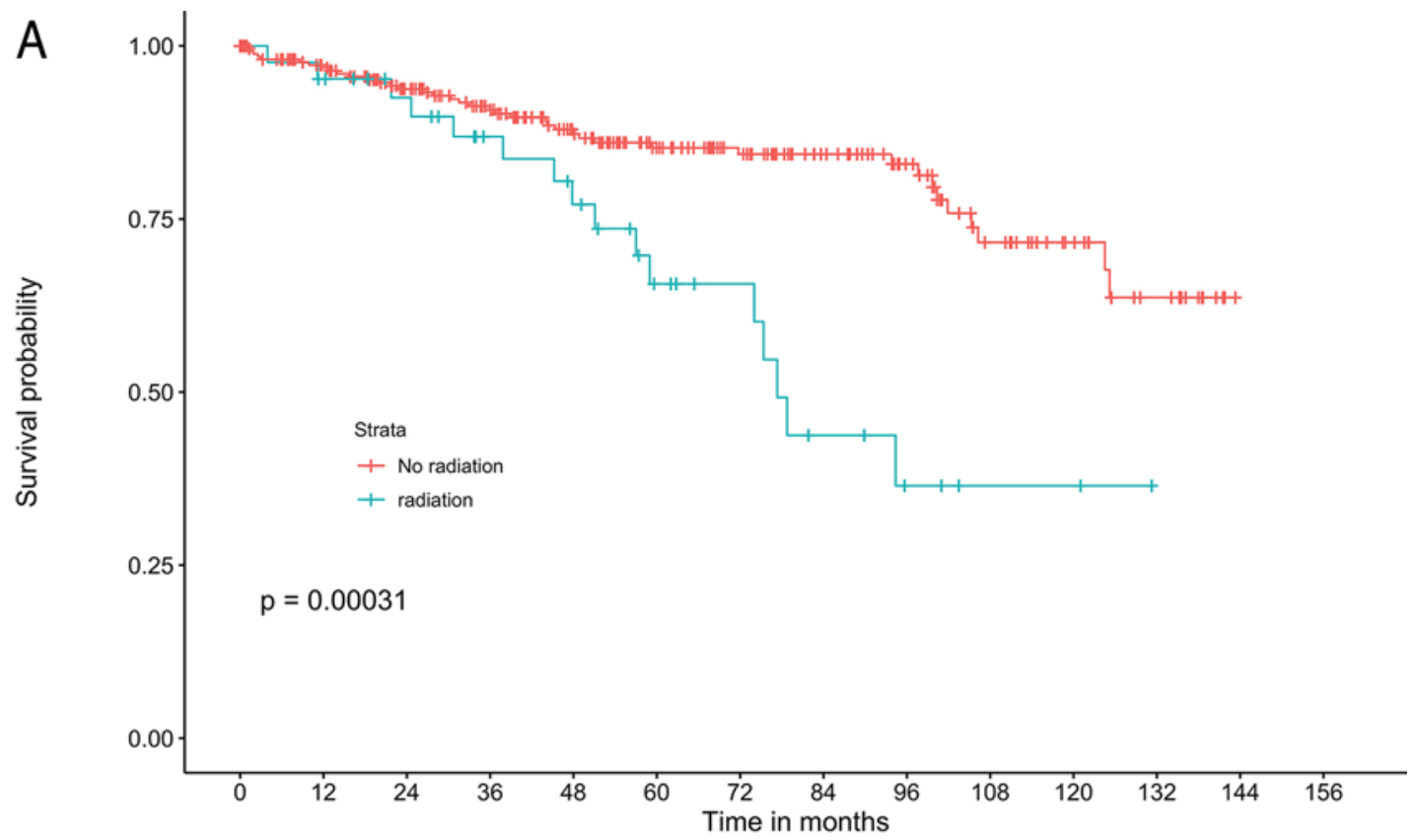

Number at risk

\begin{tabular}{|c|c|c|c|c|c|c|c|c|c|c|c|c|c|c|}
\hline \multirow{3}{*}{ 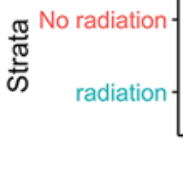 } & 266 & 235 & 202 & 172 & 140 & 113 & 92 & 71 & 53 & 32 & 22 & 12 & 0 & 0 \\
\hline & 42 & 39 & 34 & 27 & 23 & 15 & 12 & 7 & 4 & 2 & 2 & 0 & 0 & 0 \\
\hline & 0 & 12 & 24 & 36 & 48 & 60 & 72 & 84 & 96 & 108 & 120 & 132 & 144 & 156 \\
\hline
\end{tabular}

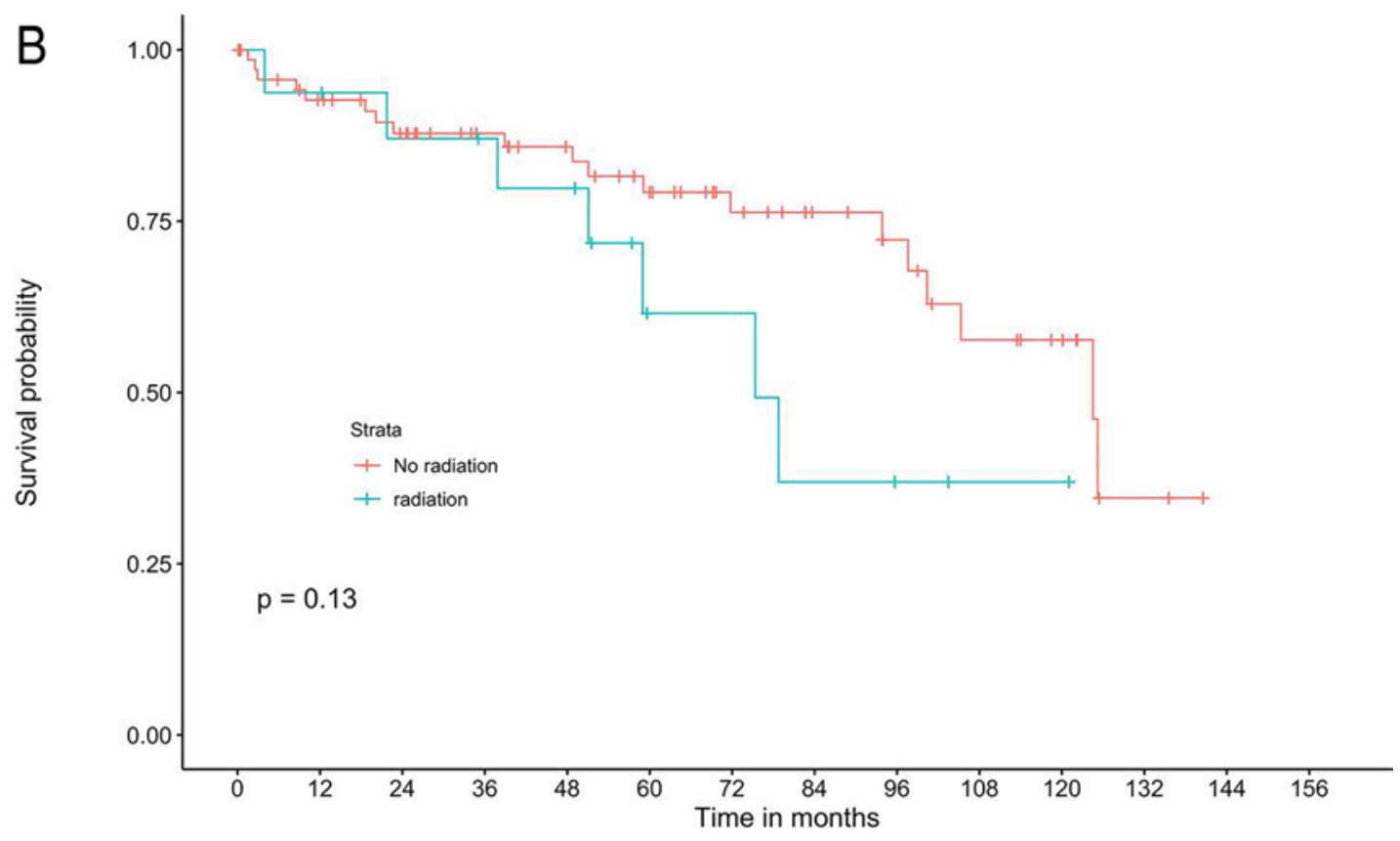

Number at risk

FIG. 3. Kaplan-Meier survival curves depicting overall survival in patients with borderline or malignant spinal meningiomas (A) and in patients with malignant meningiomas (B) who did or did not receive adjuvant radiation following surgery. 
TABLE 5. Cox proportional hazards analysis for the impact of adjuvant radiation on mortality in patients with borderline or malignant tumors

\begin{tabular}{|c|c|c|c|c|}
\hline \multirow[b]{2}{*}{ Variable } & \multicolumn{2}{|c|}{$\begin{array}{c}\text { Borderline or } \\
\text { Malignant }(n=308)\end{array}$} & \multicolumn{2}{|c|}{ Malignant Only $(n=88)$} \\
\hline & $\begin{array}{c}\mathrm{HR} \\
(95 \% \mathrm{Cl})\end{array}$ & $\begin{array}{c}p \\
\text { Value }\end{array}$ & $\begin{array}{c}\mathrm{HR} \\
(95 \% \mathrm{Cl})\end{array}$ & $\begin{array}{c}p \\
\text { Value }\end{array}$ \\
\hline Age & $1.03(1.01-1.10)$ & & $0.98(0.96-1.01)$ & 0.34 \\
\hline Sex & & & - & - \\
\hline Female & Reference & & & \\
\hline Male & $1.86(1.02-3.1)$ & 0.04 & $1.96(0.7-5.8)$ & 0.22 \\
\hline Extent of resection & & & - & - \\
\hline GTR & Reference & & & \\
\hline No GTR & $0.23(0.03-1.7)$ & 0.15 & & \\
\hline Unknown & $0.74(0.38-1.4)$ & 0.37 & & \\
\hline Tumor size & & & - & - \\
\hline$<3 \mathrm{~cm}$ & Reference & & & \\
\hline$>3 \mathrm{~cm}$ & $1.11(0.51-2.5)$ & 0.79 & & \\
\hline Missing data & $1.14(0.60-2.2)$ & 0.69 & & \\
\hline Radiation & & & - & - \\
\hline No & Reference & & Reference & \\
\hline Yes & $2.12(1.02-4.1)$ & 0.02 & $1.18(0.39-3.7)$ & 0.77 \\
\hline \multicolumn{5}{|l|}{ Behavior } \\
\hline Borderline & Reference & & - & - \\
\hline Malignant & $1.77(1.01-4.1)$ & 0.04 & & \\
\hline
\end{tabular}

$\mathrm{n}=$ number of patients.

Boldface type indicates statistical significance. No more than one predictor was added for every 10 outcome events. Data on tumor size and extent of resection were missing in 42 and 54 cases, respectively, precluding inclusion in the model.

(62\% vs 79\%), log-rank comparison did not show a statistically significant difference in survival $(p=0.13$; Fig. 3B). Cox proportional hazards analysis (adjusted for age and extent of resection) also did not demonstrate a significant difference in mortality (HR 1.18, 95\% CI 0.39-3.7, p $=0.77$, reference $=$ no radiation). Table 5 summarizes the results of the adjusted Cox analysis.

\section{Discussion}

The current analyses of 268 patients with spinal meningiomas from a national cancer database revealed no significant changes in the trends of radiation use over the last decade. Moreover, tumor size and behavior (benign, borderline, or malignant) were found to be the most prominent factors associated with the involvement of radiation in overall management. We also found that patients who received radiation as an adjunct to surgery were more likely to receive EBRT, whereas those receiving radiation as the only treatment were more likely to undergo SRS.

Agarwal et al. reported on an analysis of the Surveillance, Epidemiology, and End Results (SEER) Program, in which they evaluated trends in the management of cranial meningioma. ${ }^{1}$ In contrast to our findings, an increasing inclination toward radiotherapy was seen as the years progressed. ${ }^{1}$ Moreover, Agarwal and colleagues noted a higher utilization of surgery for larger tumors. We noted a similar trend for the use of both surgery and radiation for larger tumor sizes in spinal meningiomas.

Although the literature on spinal meningiomas is not as extensive as that on cranial meningiomas, it is generally accepted that resection is the main modality for first-line management. ${ }^{5}$ In contrast, the use of radiation in addition to surgery in the management of meningiomas is reported as the treatment of choice for recurrent tumors. ${ }^{14,21,23}$ Moreover, radiotherapy/radiosurgery after resection has been reported for large or atypical/anaplastic tumors. . $^{13,16,26}$ Adjuvant radiotherapy has also been used among patients with spinal meningioma who had a concurrent or previous cranial meningioma. ${ }^{19}$ Results from the present study are consistent with the previous literature, showing increased odds of radiation use with tumors that are larger and with borderline or malignant behavior. ${ }^{19}$

Radiation as a sole treatment for meningiomas has also been reported and is hypothesized to provide outcomes comparable to those obtained with surgery. ${ }^{7}$ Radiation can prove to be a feasible treatment option, especially in cases in which complete resection is not possible because of anatomical difficulty in surgical access. Kufeld et al. reported on a series of 11 patients with WHO grade I spinal meningioma who were treated with radiotherapy only. ${ }^{15}$ After a follow-up period of 18 months, no progression was detected and there were no myelopathic signs. Similarly, Pandit et al. described an analysis of 16 patients with optic nerve sheath meningioma, revealing significant improvement in patients' visual function and suggesting radiotherapy as an alternative to surgery. ${ }^{20}$ Overall, among the available techniques, radiosurgery is reported in the literature more frequently than EBRT, which is consistent with the current analysis. ${ }^{3,4}$

Finally, we found insufficient evidence to conclude that the addition of adjuvant radiation to overall management confers a survival benefit for patients with borderline or malignant tumors. However, significant improvements in progression-free survival have been noted with the use of radiation in previous studies. ${ }^{19}$ Since the NCDB does not capture recurrence, progression-free survival could not be assessed in our study.

\section{Study Limitations}

There are limitations to the present study. First, among the 10,458 patients with spinal meningioma in the database, we found only 268 patients who had received radiotherapy or undergone radiosurgery. Tumor size and extent of resection were also missing for a significant number of cases. Therefore, our findings could be limited by a type 1 error. Second, the NCDB does not record recurrence, toxicity, and other patient-reported outcomes, which are pertinent factors in deciding on management. It is well reported in the literature that radiation is frequently utilized in the management of recurrent meningiomas. ${ }^{25}$ However, given a lack of information, we could not determine the impact of radiation on progression-free survival. Radiation toxicity and related patient-reported outcomes are important measures to assess the feasibility of radiation use in any oncological condition. ${ }^{9,10}$ Radiation-induced myelopathy is an important complication that warrants further 
investigation. ${ }^{8}$ Third, we could not study cause-specific mortality, as that is not available in the NCDB. Although meningioma is not associated with high rates of mortality, disease-specific mortality is an important outcome to assess, and the lack of this variable limits our ability to make conclusive recommendations.

\section{Conclusions}

A study of patients with spinal meningiomas from a national cancer database revealed a small increase in the utilization of radiation for the management of spinal meningioma without a significant increase in overall survival. Larger tumor size and borderline or malignant behavior were found to be associated with increased radiation use. Further studies assessing the efficiency of radiation in the management of atypical or anaplastic meningiomas should be performed to better understand the role of radiation in the management of spinal meningiomas.

\section{References}

1. Agarwal V, McCutcheon BA, Hughes JD, Carlson ML, Glasgow AE, Habermann EB, et al: Trends in management of intracranial meningiomas: analysis of 49,921 cases from modern cohort. World Neurosurg 106:145-151, 2017

2. Ames CP, Boriani S, Jandial R (eds): Spine and Spinal Cord Tumors: Advanced Management and Operative Techniques. Boca Raton: CRC Press, 2013

3. Bir SC, Ambekar S, Ward T, Nanda A: Outcomes and complications of gamma knife radiosurgery for skull base meningiomas. J Neurol Surg B Skull Base 75:397-401, 2014

4. Bledsoe JM, Link MJ, Stafford SL, Park PJ, Pollock BE: Radiosurgery for large-volume $\left(>10 \mathrm{~cm}^{3}\right)$ benign meningiomas. J Neurosurg 112:951-956, 2010

5. Bydon M, Gokaslan ZL: Spinal meningioma resection. World Neurosurg 83:1032-1033, 2015

6. Deyo RA, Cherkin DC, Ciol MA: Adapting a clinical comorbidity index for use with ICD-9-CM administrative databases. J Clin Epidemiol 45:613-619, 1992

7. Di Franco R, Borzillo V, Ravo V, Falivene S, Romano FJ, Muto M, et al: Radiosurgery and stereotactic radiotherapy with cyberknife system for meningioma treatment. Neuroradiol J 31:18-26, 2018

8. Dodd RL, Ryu MR, Kamnerdsupaphon P, Gibbs IC, Chang SD Jr, Adler JR Jr: CyberKnife radiosurgery for benign intradural extramedullary spinal tumors. Neurosurgery 58:674-685, 2006

9. El Shafie RA, Czech M, Kessel KA, Habermehl D, Weber D, Rieken S, et al: Clinical outcome after particle therapy for meningiomas of the skull base: toxicity and local control in patients treated with active rasterscanning. Radiat Oncol 13:54, 2018

10. Farzin M, Molls M, Kampfer S, Astner S, Schneider R, Roth $\mathrm{K}$, et al: Optic toxicity in radiation treatment of meningioma: a retrospective study in 213 patients. J Neurooncol 127:597606,2016

11. Gottfried ON, Gluf W, Quinones-Hinojosa A, Kan P, Schmidt MH: Spinal meningiomas: surgical management and outcome. Neurosurg Focus 14(6):e2, 2003

12. Guidetti B: Removal of extramedullary benign spinal cord tumours, in Krayenbühl H, Brihaye J, Loew F, et al (eds): Advances and Technical Standards in Neurosurgery. Vienna: Springer, 1974, pp 173-197

13. Hwang KL, Hwang WL, Bussière MR, Shih HA: The role of radiotherapy in the management of high-grade meningiomas. Chin Clin Oncol 6 (Suppl 1):S5, 2017
14. Kim M, Lee DH, Kim Rn HJ, Cho YH, Kim JH, Kwon DH: Analysis of the results of recurrent intracranial meningiomas treated with re-radiosurgery. Clin Neurol Neurosurg 153:93-101, 2017

15. Kufeld M, Wowra B, Muacevic A, Zausinger S, Tonn JC: Radiosurgery of spinal meningiomas and schwannomas. Technol Cancer Res Treat 11:27-34, 2012

16. Magill ST, Young JS, Chae R, Aghi MK, Theodosopoulos PV, McDermott MW: Relationship between tumor location, size, and WHO grade in meningioma. Neurosurg Focus 44(4):E4, 2018

17. Malik GM, Tomecek FJ: Spinal cord meningiomas. Contemp Neurosurg 13(3):1-5, 1991

18. Morandi X, Haegelen C, Riffaud L, Amlashi S, Adn M, Brassier G: Results in the operative treatment of elderly patients with spinal meningiomas. Spine (Phila Pa 1976) 29:2191-2194, 2004

19. Noh SH, Kim KH, Shin DA, Park JY, Yi S, Kuh SU, et al: Treatment outcomes of 17 patients with atypical spinal meningioma, including 4 with metastases: a retrospective observational study. Spine J 19:276-284, 2019

20. Pandit R, Paris L, Rudich DS, Lesser RL, Kupersmith MJ, Miller NR: Long-term efficacy of fractionated conformal radiotherapy for the management of primary optic nerve sheath meningioma. Br J Ophthalmol [epub ahead of print], 2018

21. Pereira BJA, de Almeida AN, Paiva WS, Teixeira MJ, Marie SKN: Impact of radiotherapy in atypical meningioma recurrence: literature review. Neurosurg Rev [epub ahead of print], 2018

22. Riemenschneider MJ, Perry A, Reifenberger G: Histological classification and molecular genetics of meningiomas. Lancet Neurol 5:1045-1054, 2006

23. Roux FX, Nataf F, Pinaudeau M, Borne G, Devaux B, Meder JF: Intraspinal meningiomas: review of 54 cases with discussion of poor prognosis factors and modern therapeutic management. Surg Neurol 46:458-464, 1996

24. Sahgal A, Chou D, Ames C, Ma L, Lamborn K, Huang K, et al: Image-guided robotic stereotactic body radiotherapy for benign spinal tumors: the University of California San Francisco preliminary experience. Technol Cancer Res Treat 6:595-604, 2007

25. Walcott BP, Nahed BV, Brastianos PK, Loeffler JS: Radiation Treatment for WHO Grade II and III Meningiomas. Front Oncol 3:227, 2013

26. Wang C, Kaprealian TB, Suh JH, Kubicky CD, Ciporen JN, Chen Y, et al: Overall survival benefit associated with adjuvant radiotherapy in WHO grade II meningioma. Neuro Oncol 19:1263-1270, 2017

\section{Disclosures}

The authors report no conflict of interest concerning the materials or methods used in this study or the findings specified in this paper.

\section{Author Contributions}

Conception and design: Yolcu, Goyal. Acquisition of data: Yolcu, Goyal. Analysis and interpretation of data: Yolcu, Goyal, Alvi. Drafting the article: Yolcu, Goyal, Alvi, Moinuddin. Critically revising the article: all authors. Reviewed submitted version of manuscript: all authors. Approved the final version of the manuscript on behalf of all authors: Bydon. Statistical analysis: Yolcu, Goyal, Alvi. Administrative/technical/material support: Bydon. Study supervision: Bydon.

\section{Correspondence}

Mohamad Bydon: Mayo Clinic, Rochester, MN. bydon. mohamad@mayo.edu. 